\title{
Social Work Students and the Research Process: Exploring the Thinking, Feeling, and Doing of Research
}

Tina Maschi, Carolyn Bradley, Robert Youdin, Mary Lou Killian, Carol Cleaveland, and Rosemary A. Barbera

The purpose of this pilot study was to explore how social work students enrolled in a research course report their thoughts, feelings, and satisfaction with the research process. A pretest and posttest, self-report measures, the State-Trait Anxiety Scale (Y1), and subscales of the Research Process Survey were used to track the thoughts, feelings, and actions of 111 social work research students during a fifteen-week semester. Results of paired sample t-tests revealed that although social work students experienced a decrease in negative thoughts and feelings (e.g., anxiety) about the research process, they were not satisfied with it. These findings have important implications for social work education. Helping students increase not only their positive thoughts and feelings about research but also their satisfaction level can assist with the long-term educational goal to educate social work professionals who can provide high-quality services, evaluate practice, and improve practice, policy, and social service delivery.

Keywords: CSWE accreditation standards, social work education, research, teaching, student writing, student satisfaction, library research

Research coursework is an inevitable part of every social work student's educational experience and a formative step that shapes how he or she will integrate research knowledge and skills into professional practice. The Council of Social Work Education (2002) Educational Policy and Accreditation Standards mandates that social work education programs provide "qualitative and

Tina Maschi, Ph.D., LCSW, ACSW, is assistant professor in the Fordham University Graduate School of Social Service, New York City. Carolyn Bradley, Ph.D., LCSW. LCADC, is assistant professor in the Monmouth University Department of Social Work in West Long Branch, New Jersey. Robert Youdin, Ph.D., is lecturer and Mary Lou Killian, Ph.D., is specialist professor in the Monmouth University Department of Social Work, West Long Branch, New Jersey. Carol Cleaveland, Ph.D., LSW, is assistant professor, George Mason University in Fairlax, Virginia. Rosemary A. Barbera, Ph.D., MSS, MA, is assistant professor in the Monmouth University Department of Social Work.

The Journal of Baccalaureate Social Work, Vol, 13, No. 1 (2007)

(C) 2007 by the Association of Baccalaureate Social Work Program Directors. All rights reserved. 
quantitative research content" with the explicit purpose that social work students learn to "develop, use, and effectively communicate empirically based knowledge and evidence-based interventions" (p. 12). A common method used to evaluate social work students' attainment of research knowledge and skills is to require students to write a research proposal or report, a task to which social work research texts often dedicate at least a chapter (e.g., Engel \& Schutt, 2005; Friedman, 2006; Kreuger \& Neuman, 2005). Conducting research and writing a research report are often carried out over the course of one or two semesters and require social work students to identify a topic, conduct a library literature search, organize and synthesize the literature, craft research questions and/or hypotheses, develop a research design, propose and/or carry out the study, and write the final report.

As systematic as this type of research assignment sounds, more than two decades of literature suggests that social work students often experience negative emotional, cognitive, or behavioral responses to research coursework, particularly during the initial learning stages (Adam, Zosky, \& Unrau, 2004; Briar, Weissman, \& Rubin, 1981; Secret, Ford, \& Rompf, 2003; Taylor, 1990). These common negative feelings, thoughts, and behaviors include anxiety and fear, self-doubt and confusion, and procrastination and task aversion (Davis, 2003; Forte, 1995; Royce \& Rompf, 1992; Wilson \& Rosenthal, 1993). Research also suggests that prolonged engagement in research often increases students' sense of self-efficacy and confidence about research (Holden, Anastas, \& Meenaghan, 2003; Holden, Meenaghan, Anastas, \& Metrey, 2002). Although we have a general understanding of students' affective or cognitive processes of research, we have yet to fully explore how the interaction of thoughts, feelings, and actions affects social work students' comprehension and overall satisfaction with the research process. Gaining a better understanding of this process can help educators to identify what emotional, cognitive, and behavioral factors affect social work students' integration of research knowledge and skills into practice. This information can also be used to develop and improve teaching strategies for students to effectively navigate the thinking, feeling, and doing of research, especially among BSW students, who are often new to research coursework.

The library science profession offers a potential explanation for students' experiences conducting library research for research papers (Jiao \& Onwuegbuzie, 1999; Kracker, 2002). In particular, Carol Kuhlthau (2005) proposed the Information Search Process model, which is a six-stage process and outcome model that describes the dynamic process of students' emotions, cognitions, and behaviors from the start of the library information search process to the conclusion of the final paper. A progression of thoughts, feelings, and actions are commonly associated with the six steps in the process model, which consists of task initiation, topic selection, prefocus exploration, focus formation, information collection, and search closure.

More than two decades of empirical research on Kuhlthau's Information Search Process model suggests that students' initial feelings of confusion and 
anxiety at the start of the research assignment (i.e., task initiation and topic selection) commonly transform to confidence, competence, and satisfaction at project completion and search closure (Kuhlthau, 2005; Kuhlthau \& Tama, 2001). Similarly, initial vague thoughts about what and how to research often become focused as the project progresses and certain action strategies are used (Kuhlthau, 1993). Despite the longitudinal validation of the Information Search Process model with a wide array of groups such as high school and college students, legal professionals, and public library users (Kuhlthau, 1988, 1993; Kuhlthau \& Tama, 2001; Kuhlthau, Turock, George, \& Belvin, 1990), the interaction of thoughts and feelings and satisfaction with the research process has not yet been fully explored with social work students.

Therefore, the purpose of this outcome study is to build upon the extant literature by exploring the affective (feelings) and cognitive (thoughts) dimensions among social work students enrolled in a research course that required a final research paper. A pre- and posttest design and a purposive sample using the standardized State-Trait Anxiety Scale (Spielberger, 1983) and the Research Process Survey (Kracker, 2002) were used to examine the thoughts, feelings, and actions of 111 northeastern United States social work students enrolled in a research course. The research question that guided the investigation was, How do social work students enrolled in a research course describe their thoughts, feelings, and satisfaction with the research process at the beginning and completion of a research course that required students to conduct research and write a final report?

Based on a review of the literature, the following hypotheses were tested: Social work students enrolled in a research course will report significantly higher levels of anxiety about the research process at pretest levels than at posttest levels. Social work students enrolled in a research course will report significantly lower levels of positive thoughts, feelings, and satisfaction about the research process at pretest than at posttest levels.

Results of a series of paired $t$-tests revealed a statistically significant decrease in anxiety and an increase in overall thoughts and feelings about the research process. However, students also reported a decrease in overall satisfaction. These findings suggest that students' thoughts and feelings at the beginning and end of a research course can significantly change for better or worse. As these findings demonstrated, although social work students experienced a decrease in negative thoughts and feelings (e.g., anxiety) about the research process, this did not also mean they were satisfied with it.

Research on social work students' experiences of learning research has important implications for social work practice, education, and research. And increased understanding of the co-occurring thoughts, feelings, and actions of social work research students can assist educators and students to normalize common thoughts and feelings about the research process. Strategies also can be developed or improved to enhance their confidence and competence with the process. This increased confidence and competence may in turn translate into 
their professional lives with the explicit goal of using their research knowledge and skills to "provide high-quality services; to initiate change; to improve practice, policy, and social service delivery; and to evaluate their own practice" (Council on Social Work Education, 2002, p. 12).

\section{Method}

\section{Research Design}

An investigation of social work students' experiences of the research process was conducted in 2005 during the fifteen-week fall semester. The setting was a private midsized liberal arts university in the northeastern United States. The BSW students ( 2 percent; $n=120$ ) and MSW students ( 3 percent; $n=210$ ) represented 5 percent of the approximate total student population of 6,100 . A pretest and posttest design and a Web-based self-report survey were used to track the thoughts, feelings, and actions of a purposive sample of social work students enrolled in a social work research coursework.

\section{Sample}

The target population was 153 social work students enrolled in BSW or MSW research courses. Invitations were sent to the 153 students, and 111 social work students agreed to participate in the online survey, resulting in a 73 percent response rate. The majority of the 111 participants were female ( 82 percent; $n=92$ ), between the ages of nineteen and twenty-four ( 41 percent; $n=45)$, and white (79.5 percent; $n=89$ ). Most of them were full-time students (79 percent; $n=78$ ). About one-quarter of the sample (23.8 percent; $n=25$ ) were BSW students, and the majority ( 76 percent; $n=79$ ) were MSW students. About one of out five students $(n=23)$ reported having no prior research course.

\section{Measures}

The measures for this investigation were used to chronicle the thoughts and feelings of social work students at the beginning (time 1) and end (time 2) of a research assignment. Pretest (baseline) and posttest surveys that included Spielberger's standardized State-Trait Anxiety Scale were used to track their thoughts and feelings, and the subscales of Kracker's Research Process Survey were used to track their overall feelings and thoughts and satisfaction with the research process. The Culturally Competent Socio-Demographic Questionnaire (Maschi, Youdin, \& Bradley, 2005) was used to gather relevant sociodemographic information.

Anxiety Anxiety was conceptually defined as an "unpleasant emotional state or condition" (Spielberger, 1983, p. 4) often consisting of subjective feelings of tension, apprehension, nervousness, and worry. It was operationalized using the standardized state anxiety form, a self-report survey that consists of twenty 
items that use a four-item Likert scale $(1=$ not at all, $2=$ somewhat, $3=$ moderately so, and $4=$ very much so). Participants who complete the survey are asked to describe how they generally feel about their most recent research experience. It includes both negative and positive statements such as "I feel calm." "I am tense," "I feel self-confident," "I feel confused," and "I feel pleased." Negative statements were reverse scored prior to the preparation of the summative scale for data analysis purposes.

Thoughts, feelings, and satisfaction with the research process The research process was conceptualized as an awareness of the cognitive and affective dimensions of the research process (Kuhlthau, 2005). It was operationalized by using three subscales of the eighteen-item Research Process Survey. Developed by Kracker (2002), the Research Process Survey is a self-report survey used to measure students' cognitive and affective awareness and satisfaction with the research process consistent with Kuhlthau's Information Search Process Model. Social work research students were asked to respond to positive and negative statements about the research process by using a five-point Likert scale ( $1=$ strongly disagree, 2 = disagree, $3=$ sometimes, $4=$ agree, $5=$ strongly agree).

For the purposes of this investigation, three subscales regarding the research process were used: overall thoughts, overall feelings, and satisfaction. The first additive scale, overall thoughts about the research process, consisted of the following two items: "I don't understand how to do research" and "When looking for a research topic, I usually go with the first idea that comes to mind." The second additive scale, overall feelings about the research process, was measured using the following two items: "Overall, I dislike the research process" and "I am comfortable with research paper assignments." The third additive scale, satisfaction with the research process, was composed of the following two items: "I generally feel satisfied with my research" and "I usually feel disappointed with my research." Negatively worded items were recoded in the reverse direction prior to data analysis.

Demographic variables Maschi, Youdin, and Bradley's Culturally Competent Socio-Demographic Questionnaire was used to collect demographic information during the initial data collection (time 1). For the purposes of this analysis, the following demographic information was used: student status, age, gender, and race/ethnicity. Student status was measured as a dichotomous variable. Social work students responded that they were BSW or MSW students $(0=\mathrm{BSW}$; $1=\mathrm{MSW})$. Age was measured as a continuous variable and determined by the question "What is your age in years?" Gender was measured as either male or female (male $=0$; female $=1$ ). Race/ethnicity was determined by the question "What is your race/ethnicity?" in which respondents could choose from seven categories: white (not of Hispanic origin), African American, Hispanic, Asian/Pacific Islander, American Indian/Alaskan Native, interracial, and other race/ethnicities not listed. For the purposes of the analysis, race/ethnicity was coded as a binary variable (majority or white $=1$; minority $/$ nonwhite $=0$ ). 
Data Collection Procedures

Data were collected from BSW and MSW students enrolled in research courses at the beginning (pretest) and end (posttest) of the research course. During the fall 2005 term, twelve social work research course sections were offered, of which three were BSW courses (i.e., two foundation social work research courses and one data analysis course). Of the nine MSW courses, one section was a foundation research course and the other eight sections were advanced research methods (i.e., three practice evaluation course, one program evaluation course, and four courses on the implications and applications of social justice and human rights).

Social work students enrolled in at least one of these research courses were invited to participate in the study via an e-mail invitation. This e-mail invitation provided a link to the secure online survey, which generated a unique token number or study identification number. Two e-mail reminders were sent to students who did not complete the survey within three days of the initial invitation, and then within seven days. Students who did not respond to the initial e-mail invitation and two e-mail reminders were then dropped from the participant pool. The anonymous token number provided in the e-mail was used to match students' pretest and posttest measures.

The study was approved by the university internal review board, and students had to provide voluntary informed consent via the Web-based link in order to complete the survey. The students took the survey at the beginning (week 1 pretest survey) and end (week 15 posttest) of the semester; it took about fifteen to twenty minutes to complete. The online survey results were automatically uploaded to an Excel spreadsheet that was transferred to Statistical Software for the Social Sciences for the purposes of data analysis.

\section{Data Analysis}

Statistical Software for the Social Sciences 14.0 was used to analyze the hypotheses about social work students and the research process. A series of analyses was conducted, including descriptive statistics and paired $t$-tests of time 1 and time 2 anxiety and affective and cognitive processes about the research process. Cases with missing data were dropped from the analyses for the anxiety, overall thoughts, and feelings scales, resulting in eighty-seven cases. Cases with missing data were dropped from the analysis of the satisfaction scale, resulting in eighty-two cases. Since the overall sample was largely homogeneous, no significant differences were noted between the sample retained and the full sample.

\section{Findings}

In order to test the study hypotheses, a series of dependent paired $t$-tests was conducted. The dependent or paired samples $t$-test was used for the single sample of social work research students in order to compare their pre- and post- 
test mean scores on the variables of central interest: anxiety, overall thoughts, overall feelings, and satisfaction with the research process.

The results of the dependent paired $t$-test for anxiety show a significant difference between pretest and posttest anxiety scores. As shown in table 1, the mean score of the pretest levels of anxiety (t1 anxiety) is 68.09, compared to 63.47 at posttest ( $\mathrm{t} 2$ anxiety), a decrease of 4.62 . The 4.62 point difference is statistically significant at the .01 level, with 86 degrees of freedom. As shown in table 2, pre- and posttest anxiety scores show a significant decrease in levels of anxiety among social work students enrolled in research courses $\left(t_{\mathrm{dar}}=86\right)=$ $2.08 ; p=.02$ ).

Results of the dependent paired $t$-test for the overall thoughts scale revealed a pretest mean score ( $\mathrm{t} 1$ thoughts) of 6.56 , whereas the posttest mean score ( $\mathrm{t} 2$ thoughts) was 6.89 (see table 1). The difference between time 1 and time 2 thoughts was 0.32 . As shown in table 2 , the 0.32 point difference is statistically significant $(p=.034)$, with 86 degrees of freedom. The pre- and posttest scores show a significant change in social work research students' overall positive thoughts about the research process $\left.\left(t_{(\mathrm{df} ;}=8 \mathrm{86}\right)=-1.85 ; p=.034\right)$.

The mean scores of overall.feelings about the research process were examined next. As shown in table 1, the pretest mean score (t1 feelings) was 4.64, and the posttest mean score was 6.40. The difference was 1.76. As shown in table 2 , the 1.76 point increase is statistically significant at the .01 level with 86 degrees of freedom, which suggests a significant change in social work students'

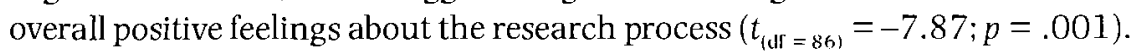

'The next dependent paired $t$-test comparing social work students' pretest and posttest scores for overall satisfaction showed a pretest mean score of 5.35 , compared to the posttest mean score of 5.05 (see table 1). The difference between time 1 and time 2 satisfaction scores was 0.31 . As displayed in table 2 , the 0.31 point decrease is statistically significant $(p=.022)$, with 81 degrees of freedom $\left(t_{\mathrm{tdr}=81)}=2.03 ; p<.05\right)$. This finding suggests that overall satisfaction

Table 1 Mean scores of social work students' anxiety, overall thoughts, feelings, and satisfaction scores between pretest and posttest measures

\begin{tabular}{lrrr}
\hline Variables & $M$ & $N$ & $5 D$ \\
\hline T1 Anxiety & 68.09 & 87 & 18.48 \\
T2 Anxiety & 63.47 & 87 & 20.60 \\
T1Overall thoughts & 6.56 & 87 & 1.80 \\
T2 Overall thoughts & 6.89 & 87 & 1.88 \\
T1 Overall feelings & 4.64 & 87 & 1.97 \\
T2 Overall feelings & 6.40 & 87 & .80 \\
T1 Satisfaction & 5.35 & 82 & 1.27 \\
T2 Satisfaction & 5.05 & 82 & 1.27 \\
\hline
\end{tabular}


Table 2 Results of paired samples $t$-tests among social work research students between pretest and posttest measures of anxiety, overall thoughts, feelings, and satisfaction with the research process

\begin{tabular}{|c|c|c|c|c|c|c|c|c|}
\hline & \multicolumn{5}{|c|}{ Paired differences } & \multirow[b]{3}{*}{$t$} & \multirow[b]{3}{*}{$d f$} & \multirow{3}{*}{$\begin{array}{c}\text { Sig } \\
(1 \text { tailed) }\end{array}$} \\
\hline & \multirow[b]{2}{*}{ Mean dif } & \multirow[b]{2}{*}{$S D$} & \multirow[b]{2}{*}{ sem } & \multicolumn{2}{|c|}{$\begin{array}{l}95 \% \mathrm{Cl} \text { of } \\
\text { difference }\end{array}$} & & & \\
\hline & & & & Lower & Upper & & & \\
\hline T1 \& T3 anxietya & 4.62 & 20.69 & 2.08 & 0.21 & 9.03 & 2.08 & 86 & .020 \\
\hline$T 1 \& T 2$ thoughts $^{a}$ & -0.32 & 1.63 & 0.17 & -0.69 & 0.02 & -1.85 & 86 & .034 \\
\hline T1 \& T2 feeling $s^{a}$ & -1.76 & 2.09 & 0.22 & -2.20 & -1.31 & -7.87 & 86 & .001 \\
\hline T1 \& T2 satisfaction ${ }^{\mathrm{b}}$ & 0.31 & 1.36 & 0.15 & 0.01 & 0.60 & 2.03 & 81 & .022 \\
\hline
\end{tabular}

${ }^{a} N=87$

${ }^{\mathrm{b}} \mathrm{N}=82$

decreased at the completion of the research course and research report writing assignment.

In conclusion, the results of the dependent paired $t$-test show that the anxiety levels of social work students enrolled in research courses significantly decreased, and their overall positive thoughts and feelings about the research process significantly increased. However, their overall satisfaction with the research process significantly decreased between pre- and post measures. These findings warrant further discussion regarding their consistency with the extant literature and their implications for social work practice and education. A discussion of these implications follows.

\section{Discussion}

The purpose of this study was to explore the overall thoughts, feelings, and satisfaction with the research process of a sample of social work students enrolled a research course. The data from this investigation found support for the first hypothesis, which predicted that pretest anxiety levels concerning research coursework would decrease at the final posttest scores. In contrast, the data only partially support the second hypothesis. As predicted, results of a series of paired $t$-tests revealed an increase in overall positive thoughts and feelings about the research process between pre- and posttest measures. However, students were found to experience a decrease in overall satisfaction with the research process from pretest to posttest measurement. This decrease in satisfaction with the research process was in the inverse direction of what was predicted.

These findings suggest that social work students' research experiences, especially when they are conducting research and writing research reports, involve a complex interplay of thoughts, feelings, and satisfaction concerning research 
test mean scores on the variables of central interest: anxiety, overall thoughts, overall feelings, and satisfaction with the research process.

The results of the dependent paired $t$-test for anxiety show a significant difference between pretest and posttest anxiety scores. As shown in table 1, the mean score of the pretest levels of anxiety (t1 anxiety) is 68.09, compared to 63.47 at posttest ( $\mathrm{t} 2$ anxiety), a decrease of 4.62 . The 4.62 point difference is statistically significant at the .01 level, with 86 degrees of freedom. As shown in table 2, pre- and posttest anxiety scores show a significant decrease in levels of anxiety among social work students enrolled in research courses $\left(t_{(\mathrm{dr}}=86\right)=$ $2.08 ; p=.02$ ).

Results of the dependent paired $t$-test for the overall thoughts scale revealed a pretest mean score ( $t 1$ thoughts) of 6.56 , whereas the posttest mean score ( $t 2$ thoughts) was 6.89 (see table 1). The difference between time 1 and time 2 thoughts was 0.32 . As shown in table 2 , the 0.32 point difference is statistically significant $(p=.034)$, with 86 degrees of freedom. The pre- and posttest scores show a significant change in social work research students' overall positive thoughts about the research process $\left(t_{\mathrm{dd}=86)}=-1.85 ; p=.034\right)$.

The mean scores of overall feelings about the research process were examined next. As shown in table 1, the pretest mean score (t1 feelings) was 4.64, and the posttest mean score was 6.40. The difference was 1.76. As shown in table 2 , the 1.76 point increase is statistically significant at the .01 level with 86 degrees of freedom, which suggests a significant change in social work students' overall positive feelings about the research process $\left(t_{\mathrm{dr}=86)}=-7.87 ; p=.001\right)$.

The next dependent paired $t$-test comparing social work students' pretest and posttest scores for overall satisfaction showed a pretest mean score of 5.35, compared to the posttest mean score of 5.05 (see table 1). The difference between time 1 and time 2 satisfaction scores was 0.31 . As displayed in table 2 , the 0.31 point decrease is statistically significant $(p=.022)$, with 81 degrees of freedom $\left(t_{(\mathrm{dr}=81)}=2.03 ; p<.05\right)$. This finding suggests that overall satisfaction

Table 1 Mean scores of social work students' anxiety, overall thoughts, feelings, and satisfaction scores between pretest and posttest measures

\begin{tabular}{lrcr}
\hline Variables & $M$ & $N$ & $S D$ \\
\hline T1 Anxicty & 68.09 & 87 & 18.48 \\
T2 Anxiety & 63.47 & 87 & 20.60 \\
T1Overall thoughts & 6.56 & 87 & 1.80 \\
T2 Overall thoughts & 6.89 & 87 & 1.88 \\
T1 Overall feelings & 4.64 & 87 & 1.97 \\
T2 Overall feelings & 6.40 & 87 & .80 \\
T1 Satisfaction & 5.35 & 82 & 1.27 \\
T2 Satisfaction & 5.05 & 82 & 1.27 \\
\hline
\end{tabular}


Table 2 Results of paired samples $t$-tests among social work research students between pretest and posttest measures of anxiety, overall thoughts, feelings, and satisfaction with the research process

\begin{tabular}{|c|c|c|c|c|c|c|c|c|}
\hline & \multicolumn{5}{|c|}{ Paired differences } & \multirow[b]{3}{*}{$t$} & \multirow[b]{3}{*}{$d f$} & \multirow{3}{*}{$\begin{array}{c}\text { Sig } \\
(1 \text { tailed })\end{array}$} \\
\hline & \multirow[b]{2}{*}{ Mean dif } & \multirow[b]{2}{*}{$5 D$} & \multirow[b]{2}{*}{ sem } & \multicolumn{2}{|c|}{$\begin{array}{l}95 \% \mathrm{Cl} \text { of } \\
\text { difference }\end{array}$} & & & \\
\hline & & & & Lower & Upper & & & \\
\hline $\mathrm{T} 1$ \& T3 anxiety ${ }^{\mathrm{a}}$ & 4.62 & 20.69 & 2.08 & 0.21 & 9.03 & 2.08 & 86 & .020 \\
\hline$T 1 \& T 2$ thoughts $^{a}$ & -0.32 & 1.63 & 0.17 & -0.69 & 0.02 & -1.85 & 86 & .034 \\
\hline $\mathrm{T} 1 \&$ T2 feelings ${ }^{\mathrm{a}}$ & -1.76 & 2.09 & 0.22 & -2.20 & -1.31 & -7.87 & 86 & .001 \\
\hline T1 \& T2 satisfaction ${ }^{\mathrm{D}}$ & 0.31 & 1.36 & 0.15 & 0.01 & 0.60 & 2.03 & 81 & .022 \\
\hline
\end{tabular}

$N=87$

${ }^{\circ} N=82$

decreased at the completion of the research course and research report writing assignment.

In conclusion, the results of the dependent paired $t$-test show that the anxiety levels of social work students enrolled in research courses significantly decreased, and their overall positive thoughts and feelings about the research process significantly increased. However, their overall satisfaction with the research process significantly decreased between pre- and post measures. These findings warrant further discussion regarding their consistency with the extant literature and their implications for social work practice and education. A discussion of these implications follows.

\section{Discussion}

The purpose of this study was to explore the overall thoughts, feelings, and satisfaction with the research process of a sample of social work students enrolled a research course. The data from this investigation found support for the first hypothesis, which predicted that pretest anxiety levels concerning research coursework would decrease at the final posttest scores. In contrast, the data only partially support the second hypothesis. As predicted, results of a series of paired $t$-tests revealed an increase in overall positive thoughts and feelings about the research process between pre- and posttest measures. However, students were found to experience a decrease in overall satisfaction with the research process from pretest to posttest measurement. This decrease in satisfaction with the research process was in the inverse direction of what was predicted.

These findings suggest that social work students' research experiences, especially when they are conducting research and writing research reports, involve a complex interplay of thoughts, feelings, and satisfaction concerning research 
that may shift from the start to the finish of a project. This change in thoughts and feelings may in turn influence the level to which these students achieve mastery of course material, self-confidence and competence, and satisfaction with their work. Consistent with the outcomes as described by Kuhlthau's Information Search Process model, this thinking, feeling, and doing of research appears to be a dynamic process that varies between the beginning and the end of a student's research project.

This investigation builds upon the extant literature by providing a portrait of the co-occurring thoughts, feelings, and satisfaction with the process among social work students at the beginning and the end of the research coursework. These findings are consistent with other research studies that demonstrate a positive effect of social work students' sense of self-efficacy and knowledge of the research process (Holden et al., 2002, 2003; Unrau \& Grinnell, 2005). Additionally, consistent with the Information Search Process model and social work education literature, anxiety about research is common among students, especially during the initial stages of a research project (e.g., Davis, 2003; Kracker, 2002; Wilson \& Rosenthal, 1993). However, the present investigation builds upon the extant literature by simultaneously examining the overall thoughts and feelings of social work students and their satisfaction with the research process. It was found that the finding that students may report a decrease in anxiety and an increase in positive thoughts and overall feelings about the research process does not mean that students will report satisfaction with the process. Possible reasons for the discrepancy may be similar to those for negative outcomes of mandated treatment for clients: successful completion of a program does not guarantee satisfaction with the process or the results. Qualitative results from this study revealed that 98 percent of the students took a research course because it was a program requirement, not because it was a topic of interest. Perhaps if students' initial resistance to research is not actively addressed as part of the process, dissatisfaction will be the result, regardless of their comprehension of the material.

For social work educators, the finding regarding student satisfaction with research is of particular concern. While the literature addresses issues such as fear and anxiety regarding the research process (Gustavsson \& MacEachron, 2001; Hyduk \& Large, 1999), the area of student satisfaction has been left unaddressed. Continued failure to investigate how satisfaction affects student interest in research may result in an increased divide between social work researchers and other social work practitioners.

These findings also have important implications for social work practice and education. Feelings are an essential part of the research process. If feelings are an integral part of the human experience and may affect learning, ignoring them in research courses commonly associated with high anxiety may seriously undermine our profession's long-term educational objectives for social work graduates to integrate research into practice. As in social work practice situations with clients, students' feelings in the classroom --especially fear and 
anxiety about research-should not go unchecked during the research process. Ignoring this elephant in the middle of the classroom may greatly inhibit students' abilities to learn and to work logically, systematically, and effectively in their research coursework and may undermine the long-term educational goal of integration of research knowledge and skills into practice.

Although these findings have important implications for social work practice and education, methodological limitations limit confidence in the results. Limitations of the research design include the use of a small nonrandom sample from a private university in one geographic location of the United States. Therefore, these findings are not representative, nor are they generalizable to the larger population of social work students. Additionally, the use of unstandardized measures (i.e., the Research Process Survey) makes internal validity and reliability questionable. Despite these limitations, these results suggest future directions for research.

Future research should examine both students' processes and outcomes of research. In particular, future studies can examine whether completion of a research project may decrease one's desire to do research and trust of the research process. Additionally, tracking students across different points in time over the course of the semester will provide important information about students' lived experiences of research courses. These studies should incorporate the use of longitudinal mixed-methods designs. The use of qualitative data from students and teachers could provide a thick description of the complex process that is almost nonexistent in the social work literature.

As so little is known regarding the area of student satisfaction, it might best be explored through the use of qualitative methodology. Areas to be explored in such an inquiry might be formulated through the use of adult learning theories that address issues such as level of anxiety and need for encouragement (Knowles, 1990), perception of threat to success (Reynolds, 1985), types of research methodology taught, curriculum design, and instructional strategies.

Quantitative studies that use a nationally representative sample of social work students and standardized measures could enhance our understanding of social work students and the research process by providing robust findings that are representative and generalizable. A large survey study can also gather important information about the nuances of learning research in different universities of different sizes that emphasize teaching versus research missions as well as in different geographic regions, such as urban, suburban, and rural locations. Applied research in this area can assist with the development and improvement of teaching strategies that help social work students navigate the thinking, feeling, and doing of research. Assisting students to achieve mastery and satisfaction with the research process will help bridge research into practice. This mastery and satisfaction with the research process may greatly enhance the probability that they will use their knowledge and skills to provide high-quality services, evaluate practice, and improve practice, policy, and social service delivery in their professional lives. 


\section{References}

Adam, N., Zosky, D. L., \& Unrau, Y. A. (2004). Improving the research climate in social work curricula: Clarifying learning expectations across BSW and MSW research courses. Journal of Teaching in Social Work, 24(3), $1-18$.

Briar, S., Weissman, H., \& Rubin, A. (1981). Research utilization in social work education. New York: Council on Social Work Education.

Council on Social Work Education. (2002). Educational policy and accreditation standards. Retrieved September 1, 2006, from http://www.cswe.org/accreditation/EPAS/EPAS_start.htm

Davis, S. (2003). Statistics anxiety among female African American graduatelevel social work students. Journal of Teaching in Social Work, 23(3/4), 143-158.

Engel, R., \& Schutt, R. K. (2005). The practice of research in social work. Thousand Oaks, CA: Sage.

Forte, J. (1995). Teaching statistics without sadistics. Journal of Social Work Education, 31(2), 204-218.

Friedman, B. D. (2006). The research toolkit: Putting it all together (2nd ed.). Pacific Grove, CA: Brooks/Cole.

Gustavsson, N. S., \& MacEachron, A. E. (2001). Perspectives on researchrelated anxiety among BSW students. Journal of Baccalaureate Social Work, $7(1), 111-119$.

Holden, G., Anastas, J., \& Meenaghan, T. (2003). Determining attainment of the EPAS foundation program objectives: Evidence for the use of self efficacy as an outcome. Journal of Social Work Education, 39(3), 425440.

Holden, G., Meenaghan, T., Anastas, J., \& Metrey, G. (2002). Outcomes of social work education: The case for social work self efficacy. Journal of Social Work Education, 38(1), 115-133.

Hyduk, C. A., \& Large, S. J. (1999). Factors that influence fear of research in MSW students. Aretê, 23(3), 1-8.

Jiao, Q. G., \& Onwuegbuzie, A. J. (1999, November). I'll go to the library tomorrow: The role of procrastination in library anxiety. Paper presented at the Annual Meeting of the Mid-South Education Research Association, Point Clear, AL.

Knowles, M. (1990). The adult learner: A neglected species. Houston, TX: Gulf,

Kracker, J. (2002). Research anxiety and students' perceptions of research: An experiment. Part I. Effect of teaching Kuhlthau's ISP model. Journal of the American Society for Information Science and Technology. 53(4), 282-294.

Kreuger, L. W., \& Neuman, W. L. (2005). Social work research methods: Qualitative and quantitative approaches. Boston: Pearson.

Kuhlthau, C. C. (1983). The research process: Case studies and interventions with 
high school seniors in advanced placement English classes using Kelly's theory of constructs. Doctoral dissertation, Rutgers University, New Brunswick, NJ.

Kuhlthau, C. C. (1988). Perceptions of the information search process in libraries: A study of changes from high school through college. Information Processing \& Management 24(4), 419-427.

Kuhlthau, C. C. (1992). Seeking meaning: A process approach to library and information services. Westport. CT: Libraries Unlimited.

Kuhlthau, C. C. (1993). Seeking meaning: A process approach to library and information services ( 2 nd ed.). Norwood, NJ: Ablex.

Kuhlthau, C. C., \& Tama, S. (2001). Information search process of lawyers: A call for "just for me" information services. Journal of Documentation, 57, 25-53.

Kuhlthau, C. C., Turock, B. J., George, M. W., \& Belvin, R. J. (1990). Validating a model of the search process: A comparison of academic, public and school library users. Library and Information Science Research 12, 5-31.

Maschi, T., Youdin, R., \& Bradley, C. (2005). The culturally competent sociodemographic questionnaire. Unpublished measurement instrument, Monmouth University Department of Social Work, West Long Branch, NJ.

Reynolds, G. (1985). Learning and teaching in the practice of social work. Silver Spring, MD: National Association of Social Work.

Royce, D., \& Rompf, E. L. (1992). Math anxiety: A comparison of social work and non-social work students. Journal of Social Work Education, 28(3), 270-278.

Secret, M., Ford, J., \& Rompf, E. (2003). Undergraduate research courses: A closer look reveals complex social work student attitudes. Journal of Social Work Education, 39(3), 411-422.

Spielberger, C. D. (1983). State-trait anxiety inventory. Redwood. City, CA: Mind Garden.

Taylor, E. A. (1990). The numerate social worker. Journal of Social Work Education, 26(1), 25-35.

Unrau, Y. A., \& Grinnell, R. M. (2005). The impact of social work efficacy for social work students. Social Work Education, 24(6), 639-651.

Wilson, W., \& Rosenthal, B. (1993). Anxiety and performance in an MSW research and statistics course. Journal of Teaching in Social Work, 6(2), $75-85$. 